\title{
Violence and mental illness: what is the true story?
}

\section{Mohit Varshney, Ananya Mahapatra, Vijay Krishnan, Rishab Gupta, Koushik Sinha Deb}

\section{INTRODUCTION}

In public perception, mental illness and violence remain inextricably intertwined, and much of the stigma associated with mental illness may be due to a tendency to conflate mental illness with the concept of dangerousness. This perception is further augmented by the media which sensationalises violent crimes committed by persons with mental illness, particularly mass shootings, and focuses on mental illness in such reports, ignoring the fact that most of the violence in society is caused by people without mental illness. This societal bias contributes to the stigma faced by those with a psychiatric diagnosis, which in turn contributes to non-disclosure of the mental illness and decreased treatment seeking, ${ }^{1}$ and also leads to discrimination against them. The association of violence and mental illness has received extensive attention and publicity. Public perception of the association between mental illness and violence seems to have fuelled the arguments for coerced treatment of patients with severe mental illness. ${ }^{2} 3$

However, this perception is not borne out by the research literature available on the subject. Those with mental illness make up a small proportion of violent offenders. A recent meta-analysis by Large et $a l^{4}$ found that in order to prevent one stranger homicide, 35000 patients with schizophrenia judged to be at high risk of violence would need to be detained. This clearly contradicts the general belief that patients with severe mental illness are a threat.

\section{DEFINITION AND MAGNITUDE OF THE PROBLEM}

There are numerous ways of conceptualising the definition of violence, although at present there is no consensus as to which of these is the most appropriate. The

Department of Psychiatry and National DrugDependence Treatment Centre (NDDTC), All India Institute of Medical Sciences (AllMS), New Delhi, India

Correspondence to Dr Mohit Varshney, Department of Psychiatry and National Drug-Dependence Treatment Centre (NDDTC), All India Institute of Medical Sciences (AllMS), New Delhi 110029, India;

drmohitvarshney23@hotmail.com
WHO has defined violence as the intentional use of physical force or power, threatened or actual, against oneself, another person, or against a group or community, that either results in or has a high likelihood of resulting in injury, death, psychological harm, maldevelopment or deprivation'. 5 This definition includes threats, intimidation, neglect and abuse (whether physical, sexual or psychological), as well as acts of self-harm and suicidal behaviour. Although expansive and all-encompassing, it defines violence in terms of its outcomes on health and well-being rather than its characteristics as a construct that is socially or culturally determined.

Studies investigating the prevalence of violence in psychiatric patients show a wide variability, in accordance with the treatment setting in which they were conducted. The lowest prevalence rates of violence have been seen in outpatient settings $(2.3-13 \%)$, and the highest in acute care settings (10-36\%) and involuntarily committed patients (20-44\%). ${ }^{6}$ Around $10 \%$ of the patients with schizophrenia or other psychotic disorders behave violently, compared with less than $2 \%$ of the general public. ${ }^{7}$ Although this suggests that mental illness does contribute to the risk of violence, it is important to note that the 1-year population-attributable risk (PAR) of violence associated with serious mental illness alone was found to be only $4 \%$ in the ECA (Epidemiologic Catchment Area) survey. ${ }^{8}$ This implies that even if the elevated risk of violence in people with mental illness is reduced to the average risk in those without mental illness, an estimated $96 \%$ of the violence that currently occurs in the general population would continue to occur. Although a statistical relationship with violence has been demonstrated in certain severe mental disorders such as schizophrenia, however, only a small proportion of the societal violence can be attributed to persons suffering from mental disorders. ${ }^{9}$

The dynamic interaction of social and contextual factors with the clinical variables plays an important role as a determinant of violence. However, these issues have not generated sufficient interest and the emphasis continues to be on the psychiatric diagnosis or clinical variables of the patient, while looking for causal factors of violence.

\section{VIOLENT VICTIMISATION OF THE MENTALLY ILL}

Patients with severe mental illness constitute a high-risk group vulnerable to fall victims to violence in the community. Symptoms associated with severe mental illness, such as impaired reality testing, disorganised thought processes, impulsivity and poor planning and problem solving, can compromise one's ability to perceive risks and protect oneself and make them vulnerable to physical assault. $^{1011}$

Violent victimisation of persons with severe mental illness presents obvious dangers of physical trauma and impairs the quality of patients' lives. Past traumatic and victimisation experiences have been found to be significantly associated with patients' symptom severity and illness course. ${ }^{12}$ However, this issue has attracted much less attention than violent behaviour by the patients, in spite of the fact that violent victimisation of patients occurs more frequently than violent offending by the patient. ${ }^{6} 1314$

A recent review reported that the prevalence of violent victimisation ranges between $7.1 \%$ and $56 \%$, although the issue of comparability among the studies exists. ${ }^{15}$ Young age, comorbid substance use and homelessness were found to be the risk factors for victimisation. ${ }^{15}$ A relationship between victimisation and violent behaviour by patients with severe mental illness has also been suggested in numerous studies. ${ }^{16}$ However, it is not clear whether past victimisation predicts future violence, or past violence predicts future victimisation, or both.

\section{PREDICTORS OF VIOLENT BEHAVIOUR}

The relationship between mental illness and violence has been shown to be more complex than initially suspected. From viewing mental illness as a causative agent, researchers after reanalysing the NESARC (National Epidemiologic Survey on Alcohol and Related Conditions) data have confirmed that mental illness and violence are related primarily through the accumulation of risk factors of various kinds, for example, historical (past violence, juvenile detention, physical abuse, parental arrest record), clinical (substance abuse, perceived threats), dispositional (age, sex, etc) and contextual (recent divorce, unemployment, victimisation) among the mentally ill. ${ }^{17}$ In fact, for those with mental illness without 
substance use, the relationship with violence was modest at best. ${ }^{7}$

With the growing repertoire of risk assessment tools, mental health professionals are often expected to predict and manage violent behaviour, especially in an acute care setting. Diagnostically, aggressive behaviour has been linked to schizophrenia, mania, alcohol abuse, organic brain syndrome, seizure disorder and personality disorders. ${ }^{18}$ Among patients in acute psychiatric settings, young age, male sex, history of psychiatric illness, comorbid substance abuse and positive symptoms have been shown as consistent predictors of violent behaviour. Among these, the history of violence is often emphasised as the most significant predictor of future violence. ${ }^{19}$ However, overall, the identified risk indicators of violent behaviour have poor predictive validity, in the short-term and the longterm. Large epidemiological studies like the ECA study also found a substantially increased risk of violent behaviour specifically within particular demographic subgroups of participants: younger individuals, males, those of lower socioeconomic status and those having problems involving alcohol or illicit drug use. ${ }^{8}$ These risk factors were statistically predictive of violence in people with or without mental illness.

\section{Role of substance abuse}

A number of longitudinal studies have investigated the relationship between specific substance use disorders and criminal or violent outcomes and found general association between substance abuse, crime and violence. ${ }^{20-22}$ More than half of the individuals with schizophrenia and bipolar disorder have diagnosable alcohol and drug dependence. ${ }^{23}$ The risk of violent behaviour has been found to be greater in patients with substance abuse comorbidity. ${ }^{24}$ Similarly, in patients with bipolar disorder who have been violent offenders, the risk has been found to be mostly confined to patients with substance abuse comorbidity. ${ }^{25}$ Co-occurring mental illness and substance abuse has also been shown to predict violence in the community samples. $^{26}$

Substance abuse also increases the risk of criminal victimisation in people with mental illness. A study of 1839 largely homeless patients using mental health services showed a statistically significant relationship between the number of days they were intoxicated and being robbed, threatened with a weapon or beaten. ${ }^{27}$ In an Australian study of 962 individuals with psychosis, the odds of being a victim were increased in those who had a lifetime history of substance abuse. ${ }^{28}$

\section{EVIDENCE FOR AVAILABLE TREATMENT OPTIONS}

It is now well established that adequate treatment, including management of comorbid substance use, leads to better outcomes for patients with severe mental illness. This improvement lowers the risk of violence, even up to that seen in the general population. However, there is little evidence that any of the available antipsychotics have specific 'antiaggressive' properties, although clozapine may be superior to other drugs in this regard. ${ }^{29}$ Antiepileptics have shown benefit in reducing aggression in persons with intellectual disability and seizure disorder, but their effectiveness for this indication in severe mental disorders is unproven. ${ }^{30}$ Thus, the best possible strategy seems to be to the reduction in psychopathology and functional deficits.

\section{RESEARCH AND PUBLIC HEALTH CHALLENGES}

The assessment of violence-specific risk prediction in the past studies presents several limitations: unclear definition of violence, use of non-standardised scales for the evaluation of aggressive behaviour, non-homogeneous samples, absence of control groups and of prospective design in the majority of the studies. ${ }^{31}$ These limitations might explain the heterogeneity of conclusions drawn by various studies, and particularly the wide variations in risk ratios for mental illness as a contributor to the violence. An attempt to resolve this heterogeneity is important from a public health perspective as the association of violence with mental illness hampers community reintegration of people with schizophrenia.

Also, most studies have primarily examined the association between violence and severe mental illness, for example, schizophrenia, in terms of relative risk (ie, the amount of risk posed by those with schizophrenia relative to others). However, there is a dearth of literature on indices of greater public health significance, such as PAR \%: the percentage of violence in the population that can be ascribed to schizophrenia and thus could be eliminated if schizophrenia was eliminated from the population. ${ }^{32}$ A shift of research focus from relative to attributable risk will help provide a more balanced picture and prevent unnecessary stigmatisation of people suffering from severe mental illness. Another major issue is that, since causality between mental illness and violent behaviour cannot be definitively determined, these indices need to take into account the various social-related, contextual-related and comorbidity-related factors which would act as confounders. Better ways are required for presenting risk magnitudes in a comprehensive manner.

The public health importance of resolving these issues is, to a certain extent, in disassociating mental illness from the concept of dangerousness. Any attempt to resolve these issues must begin with an acceptable operational definition of violence, and clear distinctions between various types (towards self/others, verbal/ physical, intended/actual, etc) for more consistent and reliable reporting.

Additionally, studies of violence among people with mental illness must go beyond linking various conditions or categories with rates or severity of violence, and instead include a careful examination of contextual and comorbid factors, so that the complex patterns of confounding may be unravelled. It is only with such an understanding that the appropriate intervention(s) might be formulated, and provided to patients at an appropriate time and setting.

Evidence regarding the effectiveness of psychotropic drugs on violent behaviour as one of the treatment outcomes is not yet adequately researched. Moreover, investigating the effectiveness of specific psychotropic drugs on violent behaviour as an outcome is also riddled with numerous challenges. Although pharmacoepidemiological studies provide an opportunity to assess the effectiveness of psychotropic drugs in reducing incidence of violent behaviour, they are subject to a number of confounding factors. These studies have often failed to look into the individual, social, economic and contextual factors responsible for variability in the risk of violence in these patients. Similarly, randomised controlled trials to investigate the efficacy of drugs to reduce violence in particular are also mired with feasibility issues.

Violent patients are often difficult to recruit and the attrition rates are also high in such studies. Also, since the outcome has a lower rate of occurrence, the sample size of studies needs to be high. ${ }^{30}$ Moreover, conducting such studies will pose an ethical dilemma as violence in a psychiatric patient is considered as an acute emergency, warranting immediate intervention. 


\section{CONCLUSIONS}

The relationship between mental illness and violent behaviour has serious implications from a public health perspective. Since current evidence is not adequate to suggest that severe mental illness can independently predict violent behaviour, public efforts are required to deal with the discriminatory attitude towards patients suffering from mental illness as potential violent offenders. The role of medication in controlling violent behaviour along with the target symptoms needs to be further clarified. Also, the role of individual and contextual factors in mediating violence remains to be explored further, and appropriate intervention strategies need to be formulated.

Competing interests None declared.

Provenance and peer review Commissioned; externally peer reviewed.

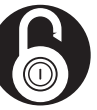

\section{OPEN ACCESS}

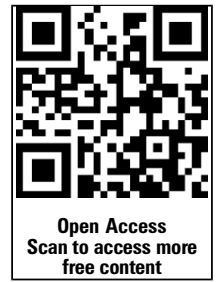

Open Access This is an Open Access article distributed in accordance with the Creative Commons Attribution Non Commercial (CC BY-NC 4.0) license, which permits others to distribute, remix, adapt, build upon this work non-commercially, and license their derivative works on different terms, provided the original work is properly cited and the use is noncommercial. See: http://creativecommons.org/licenses/ by-nc/4.0/

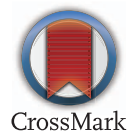

To cite Varshney M, Mahapatra A, Krishnan V, et al. J Epidemiol Community Health 2016;70:223-225.

Published Online First 28 August 2015

J Epidemiol Community Health 2016;70:223-225. doi:10.1136/jech-2015-205546

\section{REFERENCES}

1 Corrigan P. How stigma interferes with mental health care. Am Psychol 2004;58:614-25.

2 Pescosolido BA, Monahan J, Link BG, et al. The public's view of the competence, dangerousness, and need for legal coercion of persons with mental health problems. Am I Public Health 1999:89:1339-45.

3 Pescosolido BA, Martin JK, Long JS, et al. "A disease like any other?" A decade of change in public reactions to schizophrenia, depression, and alcohol dependence. Am J Psychiatry 2010;167:1321-30.

4 Large MM, Ryan CJ, Singh SP, et al. The predictive value of risk categorization in schizophrenia. Harv Law Rev 2011;19:25-33.

5 Krug E, Dalberg L, Mercy J, et al. World report on violence and health. Geneva: World Health Organization, 2002

6 Choe JY, Teplin LA, Abram KM. Perpetration of violence, violent victimization, and severe mental illness: balancing public health outcomes. Psychiatr Serv 2008;59:153-64.

7 Elbogen EB, Johnson SC. The intricate link between violence and mental disorder: results from the National Epidemiologic Survey on Alcohol and Related Conditions. Arch Gen Psychiatry 2009;66:152-61.

8 Swanson JW, Holzer CE III, Ganju VK, et al. Violence and psychiatric disorder in the community: evidence from the Epidemiologic Catchment Area surveys. Hosp Community Psychiatry 1990;41:761-70.

9 Hodgins S. Violent behaviour amongst people with schizophrenia: a framework for investigation of causes and effective treatment, and prevention. Philos Trans R Soc Lond B Biol Sci 2008;363:2505-18.

10 Goodman LA, Rosenberg SD, Mueser KT, et al Physical and sexual assault history in women with serious mental illness: prevalence, correlates, treatment, and future research directions. Schizophr Bull 1997;23:685-96.

11 Sells DJ, Rowe M, Fisk D, et al. Violent victimization of persons with co-occurring psychiatric and substance use disorders. Psychiatr Serv 2003:54:1253-7.

12 Newman JM, Turnbull A, Berman BA, et al. Impact of traumatic and violent victimization experiences in individuals with schizophrenia and schizoaffective disorder. J Nerv Ment Dis 2010;198:708-14.

13 Maniglio R. Severe mental illness and criminal victimization: a systematic review. Acta Psychiatr Scand 2009:119:180-91.

14 Brekke JS, Prindle C, Bae SW, et al. Risks for individuals with schizophrenia who are living in the community. Psychiatr Serv 2001;52:1358-66.

15 Latalova K, Kamaradova D, Prasko J. Violent victimization of adult patients with severe mental illness: a systematic review. Neuropsychiatr Dis Treat 2014:10:1925-39.

16 Hiday VA, Swanson JW, Swartz MS, et al. Victimization: a link between mental illness and violence? Int I Law Psychiatry 2001;24:

559-72.

17 Van Dorn R, Volavka J, Johnson N. Mental disorder and violence: is there a relationship beyond substance use? Soc Psychiatry Psychiatr Epidemiol 2012:47:487-503.

18 Juninger J, McGuire L. Psychotic motivation and the paradox of current research on serious mental illness and rates of violence. Schizophr Bull 2004:30:21-30

19 Amore M, Menchetti M, Tonti C, et al. Predictors of violent behavior among acute psychiatric patients: clinical study. Psychiatry Clin Neurosc 2008;62:247-55.

20 Pedersen W, Skardhamar T. Cannabis and crime: findings from a longitudinal study. Addiction 2010;105:109-18.

21 Norström T, Pape H. Alcohol, suppressed anger and violence. Addiction 2010;105:1580-6.

22 Popovici I, Homer JF, Fang $\mathrm{H}$, et al. Alcohol use and crime: findings from a longitudinal sample of U.S. adolescents and young adults. Alcohol Clin Exp Res 2012;36:532-43.

23 Kessler RC, Birnbaum H, Demler O, et al. The prevalence and correlates of nonaffective psychosis in the National Comorbidity Survey Replication (NCS-R) Biol Psychiatry 2005;58:668-76.

24 Fazel $\mathrm{S}$, Långström $\mathrm{N}$, Hjern $\mathrm{A}$, et al. Schizophrenia, substance abuse, and violent crime. JAMA 2009;301:2016-23.

25 Fazel S, Lichtenstein P, Grann M, et al. Bipolar disorder and violent crime: new evidence from population-based longitudinal studies and systematic review. Arch Gen Psychiatry 2010;67:931-8.

26 Sirotich F. Correlates of crime and violence among persons with mental disorder: an evidence-based review. Brief Treat Crisis Interv 2008:8:171-94.

27 Lam JA, Rosenheck R. The effect of victimization on clinical outcomes of homeless persons with serious mental illness. Psychiatr Serv 1998;49:678-83.

28 Happle B, Chant D, Nolan P, et al. Correlates of victimisation amongst people with psychosis. Soc Psychiatry Psychiatr Epidemiol 2004;39: 836-40.

29 Frogley C, Taylor D, Dickens G, et al. A systematic review of the evidence of clozapine's antiaggressive effects. Int I Neuropsychopharmacol 2012:15:1351-71.

30 Fazel $\mathrm{S}$, Zetterqvist J, Larsson $\mathrm{H}$, et al. Antipsychotics, mood stabilisers, and risk of violent crime. Lancet 2014;384:1206-14.

31 Huguelet $\mathrm{P}$, Perroud N. Is there a link between mental disorder and violence? Arch Gen Psychiatry 2010;67:540.

32 Walsh E, Buchanan A, Fahy T. Violence and schizophrenia: examining the evidence. $\mathrm{Br} J$ Psychiatry 2002;180:490-5. 